\title{
Recurrence and Complication Rates among Current Pterygium Treatment Techniques: Pre-operative Subpterygeal Mitomycin-C Injection, Intraoperative Mitomycin C Application and Pterygium Excision with Conjunctival Autograft
}

\author{
Archimedes L.D. Agahan, ${ }^{1,2}$ Theresa Gladiola B. Merca, ${ }^{2,3}$ Jose V. Tecson III ${ }^{4}$ and Minnette A. Panganiban ${ }^{2,5}$ \\ ${ }^{1}$ iSight Vision Center, Quezon City Philippines \\ ${ }^{2}$ Department of Ophthalmology and Visual Sciences, College of Medicine and Philippine General Hospital, University of the Philippines Manila - Manila, Philippines \\ ${ }^{3}$ The Medical City South Luzon Greenfield City, Don Jose Sta. Rosa, Laguna, Philippines \\ ${ }^{4}$ Department of Anatomy, College of Medicine, University of the Philippines Manila - Manila, Philippines \\ ${ }^{5}$ Manila Central University - Filemon D. Tanchoco Medical Foundation Hospital, Caloocan City, Philippines
}

\begin{abstract}
Objective. This study aims to determine recurrence and complication rates among patients who underwent three current pterygium treatment techniques: preoperative subpterygeal injection of mitomycin C, intraoperative application of mitomycin with pterygium excision and pterygium excision with conjunctival autograft.
\end{abstract}

Methods. This is a randomized controlled clinical trial in a tertiary hospital. We included patients with diagnosed primary pterygium and who underwent either: $A=$ pre-operative injection of $0.02 \%$ mitomycin $C$ one month prior to pterygium excision; $\mathrm{B}=$ pterygium excision with intraoperative mitomycin $\mathrm{C}$ application; or $\mathrm{C}=$ pterygium excision with conjunctival autograft.

Results. We included 111 patients: a total of 120 eyes randomized to 3 groups (A, B, C) at 40 eyes per group. After 24 months of follow-up, there was no significant difference in the recurrence rates among the groups (6/40 [15\%] in groups $A$ and $B$ and $2 / 40$ cases [5\%] in group $C ; P=0.29)$. No complications were noted in groups $B$ and $C$, while 1 case of scleral thinning was noted in group $A$. There was no significant difference in the complication rates among the three procedures $(P=1.00)$.

Conclusion. There were no significant differences in the recurrence and complication rates among the three techniques. Careful patient selection and follow-up are recommended to prevent complications such as scleral thinning.

Key Words: pterygium, subpterygeal injection, conjunctival autograft, Mitomycin-C

\section{INTRODUCTION}

Corresponding author: Archimedes Lee D. Agahan, MD iSight Vision Center

Quezon Avenue corner Timog Avenue,

Quezon City 1103, Philippines

Email: docagahan@yahoo.com
Pterygium is a fibrovascular growth of actinically damaged conjunctiva encroaching on the limbus and eventually invading the cornea. ${ }^{1}$ It is more highly prevalent in those living in tropical countries located near the equator., ${ }^{2,3}$ Ultraviolet radiation is considered a major risk factor possibly due to its actinic effect on cell mitosis, resulting in pterygium formation. ${ }^{4}$ Other factors that contribute to the development of this disease is male gender, increasing age, hereditary factors and dry eyes. ${ }^{3,45}$ Recent studies have shown that some tumor-like histologic features are evident in primary pterygia formation, such as mild dysplasia and local 
invasiveness, and increased p53 expression. ${ }^{6}$ Indications for surgical intervention include decreased visual acuity resulting from visual axis involvement, tear-film break-up, irregular eye movement limitation, eye irritation and discomfort, inability to wear contact lens, difficulty performing refractive surgery, uncertainty of the diagnosis, and cosmesis. ${ }^{1,7}$

The primary aim of surgery is to completely excise the pterygium and to prevent its recurrence. Current treatment includes excision of pterygium alone (bare sclera excision), which is considered the easiest but has high recurrence rates ranging from $24 \%$ to $91 \%$, compared to other treatment modalities. ${ }^{1,8,9}$ As such, bare sclera excision alone is no longer recommended for the treatment of pterygium. Pterygium excision with conjunctival autograft gained popularity in the 1980s and has a recurrence rate ranging from $2 \%$ to $40 \%$ with minimal complications. ${ }^{2,3,7}$ Young et al noted significant difference in the recurrence rates $(\mathrm{P}=0.04)$ between conjunctival autograft (1.9\%) and pterygium excision with intra- operative mitomycin C (15.9\%), but no significant difference in the complication rates. ${ }^{10} \mathrm{~A}$ meta-analysis on the recurrence rates after bare sclera excision with or without mitomycin $\mathrm{C}$ and use of conjunctival autograft in pterygium excision reported higher odds of pterygium recurrence specifically 6 times higher if no conjunctival autograft was done or 25 times higher if no intra/post-operative mitomycin $\mathrm{C}$ is used. ${ }^{6}$ Pterygium excision with conjunctival autograft is more technically demanding and time-consuming to perform; however, the low recurrence and complication rates make it the most acceptable technique up to this time. ${ }^{8}$

Pterygium excision is often combined with various adjunctive measures to prevent recurrence of the disease, such as use of mitomycin $\mathrm{C}$ and beta-irradiation. Mitomycin $\mathrm{C}$ is an alkylating agent that inhibits DNA synthesis and alters the shape of the fibroblasts. By inducing apoptosis of human tenon's capsule fibroblasts, it eventually inhibits its attachment and proliferation at the level of the episclera. ${ }^{1,10,11,12}$ It was first used in pterygium surgery in 1963 and has since become a popular adjunct therapy. Currently, mitomycin $\mathrm{C}$ is used in pterygium surgery as: preoperative injection, and intraoperative and post-operative topical application. Mitomycin $\mathrm{C}$ eyedrops are usually given at $0.02 \%$ concentration (range, 0.005 to 0.04 ) four times a day from 5 to 14 days post-operatively. Reported recurrence rates range from $5 \%$ to $12 \%$ but this technique has been associated with rare but significant conjunctival and corneal toxicity. ${ }^{1}$ The use of intraoperative mitomycin $\mathrm{C}$ applied directly to the scleral bed has been used in an attempt to decrease ocular morbidity. After pterygium excision, 0.02 to $0.04 \%$ mitomycin $\mathrm{C}$ is applied to the scleral bed for 2 to 5 minutes, followed by copious irrigation of 20 to $30 \mathrm{cc}$ of saline solution. This technique decreases the dosage of mitomycin $\mathrm{C}$ and the drug is applied directly to the area of interest rather than the entire ocular surface. ${ }^{1}$ Recurrence rates range from $2.7 \%$ to $44 \% .{ }^{9}$ However, despite its effectiveness in decreasing recurrence rate, its safety has been questioned due to its complications such as punctate keratitis, chemosis, delayed conjunctival wound healing, conjunctival granuloma, scleral and corneal melting. ${ }^{9}$ Any delay in the healing of the epithelium results in vascular compromise in the surgical site, which, coupled with permanent inhibition of fibroblast proliferation, exposes the area to avascular necrosis. Because of this, use of this drug is highly contraindicated in patients with dry eye and neurotrophic disease. ${ }^{1}$

Most of the complications of mitomycin $\mathrm{C}$ are associated with persistent epithelial defects and ischemic scleral necrosis, which are secondary to the direct effects of the drug on these tissues. ${ }^{1}$ Subpterygeal/subconjunctival injection of mitomycin $\mathrm{C}$ into the pterygium belly one month prior to pterygium excision has been found to be safe and effective. Since the amount of the drug is perfectly titrated and directly introduced into the lesion without spillage into the surrounding structures, epithelial toxicity is minimized and epithelial healing difficulties are avoided. ${ }^{1}$ In a study done by Donnenfeld, et al., mitomycin $\mathrm{C}$ at 0.15 $\mathrm{mg} / \mathrm{ml}$ concentration was used because it is slightly higher than the therapeutic window $(0.10 \mathrm{mg} / \mathrm{ml})$ but below the toxic level associated with cell death $(>0.3 \mathrm{mg} / \mathrm{ml}) .{ }^{1}$ This study showed a $6 \%$ recurrence rate with no wound-healing complications noted in any patient. ${ }^{1}$

In a case series study done by Khakshoor, et. al., there were only two cases of recurrence after 1 year of follow up with no serious complications noted; only whitening of the sclera and hypovascularity at the excision site were observed..$^{13}$

Antimetabolites like mitomycin $\mathrm{C}$ offer a great addition to the therapeutic regimen for pterygium. Subpterygeal/ subconjunctival injection of the drug has offered promising results with no serious complications, such as scleral and corneal melting and thinning in previous studies. Complications arising from the procedure are usually due to the following factors: poor selection of patients, follow-up, post-operative management, or method of surgery. ${ }^{14}$ Therefore, close follow-up is warranted until reepithelialization is complete. Any delay in healing should be promptly addressed to avoid scleral melt. ${ }^{14}$

The study aims to determine the recurrence and complication rates of three current techniques among patients who underwent pterygium surgery.

\section{METHODS}

The study was a randomized, controlled clinical trial that included patients referred to the External Disease and Cornea Clinic of the Department of Ophthalmology and Visual Sciences of the Philippine General Hospital, University of the Philippines Manila. Patients with other ocular diseases, previous eye surgery or with history of eye medications for the past 6 months were excluded. The hospital's ethics review committee reviewed and approved the study protocol. 
All patients signed a consent prior to being interviewed to collect demographic data and clinical history. A comprehensive ophthalmic examination was done, including: best corrected visual acuity testing using a Snellen chart, autorefraction, applanation tonometry, slit lamp biomicroscopy to examine cornea, vascularity of the conjunctiva, and sclera. An external disease consultant assessed the patients as to whom pterygium excision was indicated. Patients were randomly divided into three groups using the fishbowl method based on the surgical technique.

\section{Pterygium excision and primary closure technique}

Patient was placed in supine position, followed by application of topical anesthesia using proparacaine hydrochloride $0.5 \%$ ophthalmic solution. Subconjunctival lidocaine-epinephrine was injected in the operative site to isolate the conjunctiva from the pterygium. Pterygium head was carefully dissected from the cornea all the way to the limbal area. Blunt dissection of the pterygium from the conjunctiva and episclera and excision of pterygium was done. Conjunctival edges were closed using nylon 10-0 suture. Tobramycin-dexamethasone eye ointment was applied to the affected eye and an eye patch was placed.

\section{Preoperative injection of mitomycin C (Group A)}

Patients underwent preoperative injection of mitomycin $\mathrm{C}$ one month prior to pterygium excision and primary closure surgical technique. Topical anesthesia was applied to the affected eye, followed by injection of subconjunctival lidocaine-epinephrine in the pterygium site to isolate the conjunctiva from the pterygium. Using a Pierse forceps and a gauge 30 needle on a $1 \mathrm{cc}$ syringe, $0.1 \mathrm{cc}$ of $0.02 \%$ mitomycin $\mathrm{C}$ was injected into the belly of the pterygium, followed by use of a cotton applicator to apply pressure to the entry point for 1 minute to prevent spillage of drug. Irrigation with sterile water for injection (30 cc) was done using a $100 \mathrm{cc}$ syringe and angulated cannula. A topical antibiotic was applied post-injection. Patients were seen at the following intervals post-injection: 1 day, 1 week, 2 weeks, and 1 month. Careful and thorough ophthalmologic examination was done. Once follow up was completed, pterygium excision using primary closure technique was done.

\section{Intraoperative application of mitomycin C (Group B)}

After pterygium excision, a cotton bud soaked in mitomycin-C $0.02 \%$ for 10 seconds was applied on the root of the pterygium for 3 minutes, then washed with $30 \mathrm{cc}$ normal saline. Primary closure was then done.

\section{Conjunctival autograft (Group C)}

After application of topical anesthesia using proparacaine hydrochloride $0.5 \%$, a limbal bridle was created using spatulated polyglactin 910 (vicryl) 6-0 suture. Subconjunctival lidocaine-epinephrine was injected in the operative site to isolate the conjunctiva from the pterygium. The pterygium head was carefully dissected from the cornea all the way to the limbal area. Blunt dissection of the pterygium from the conjunctiva and episclera and excision of pterygium was done. The conjunctival defect was measured. The superior bulbar conjunctiva was marked using gentian violet. Lidocaineepinephrine was injected subconjunctivally on donor area. Careful dissection and cutting of the conjunctiva were done using vannas scissors. The donor conjunctiva was applied on the defective area and anchoring sutures were placed on four corners using nylon 10-0 suture. Additional sutures were placed around the donor conjunctiva. Tobramycindexamethasone eye ointment was applied to the affected eye and an eye patch was placed.

All patients were sent home with a pressure pack. On the first post-operative day, the pressure pack was removed and patient was sent home on a topical steroid-antibiotic 4 times a day. Follow-up was done on day 1 , week 1 , week 2, and months $1,2,3,6,12,18$, and 24 months, post-operatively. Topical drops were tapered off gradually on week 2 .

Recurrence of pterygia is defined as any fibrovascular proliferation stemming from the original pterygium site and invading onto the cornea.

Analysis of recurrence and complication rates was pre-specified to be performed through Chi-squared test of independence of a $3 \times 2$ contingency table to detect differences among groups, setting the threshold of statistical significance at $p$-value $<0.05$. Should the assumptions for the use of the said test on the contingency table (at least $80 \%$ of the cells in the table having an expected frequency of at least 5 and that no cell has an expected frequency smaller than 1) were not met with the obtained data, the FreemanHalton extension of the Fisher exact probability test for a $3 \times 2$ contingency table were to be performed instead.

The parameters of the pre-specified statistical test were also used as the basis for estimating the total sample size (in terms of eyes) using the software $G^{*}$ Power version 3.1.9.4: simulated from a set power of $80 \%$, significance level of $5 \%$ degrees of freedom of 2 (from a $3 \times 2$ table) and medium effect size of 0.3, the minimum total sample size for was determined to be 108 , divided equally to the three groups (36 each). Presuming a drop-out rate of $10 \%$, a total of 120 eyes were randomized.

\section{RESULTS}

The study included 120 eyes with primary pterygia in 111 patients. Age ranges from 21 to 78 years old, (mean age $46.84 \pm 12.24)$. There is no statistical difference in the mean age $(\mathrm{p}=0.75)$, follow up $(\mathrm{p}=0.10)$, and gender $(\mathrm{p}=0.07)$ among groups. Demographic data are shown in Table $1 .$.

Recurrence rates in groups that used mitomycin $\mathrm{C}$ were both at $15 \%$ while the group that underwent conjunctival autograft had a 5\% recurrence rate. However, recurrence rates among the groups have no statistically significant difference $(\mathrm{P}=0.29)$. Recurrences in patients with preoperative 
Table 1. Demographic characteristics of study population $(\mathrm{N}=120)$

\begin{tabular}{lcccc}
\multicolumn{1}{c}{ Characteristics } & Group A & Group B & Group C & P-value \\
Number of eyes (N=120) & 40 & 40 & 40 & - \\
Age (years) & & & & \\
$\quad$ Range & $24-78$ & $21-70$ & $22-67$ & 0.75 \\
$\quad$ Mean \pm SD & $47.18 \pm 13.24$ & $45.68 \pm 13.44$ & $47.68 \pm 10.14$ & \\
Follow-up (months) & & & & \\
$\quad$ Mean (SD) & $24.79(1.08)$ & $25.57(1.76)$ & $24.31(0.68)$ & 0.10 \\
$\quad$ Median & 24 & 24 & 24 & \\
Gender & & & & \\
$\quad$ Female & 24 & 21 & 26 & 0.07 \\
Male & 16 & 19 & & \\
\hline
\end{tabular}

Group A - Preoperative mitomycin C with pterygium excision after 1 month

Group B - Pterygium excision with intraoperative mitomycin C

Group C - Pterygium excision with conjunctival autograft

Table 2. Recurrence Rates and Complications

\begin{tabular}{lcc}
\multicolumn{1}{c}{ Group } & Recurrence No. (\%) & Complications No. (\%) \\
A: Preoperative Injection of MMC, Primary Closure $(n=40)$ & $6(15 \%)$ & 1 Scleral thinning (2.5\%) \\
B: Intraoperative Application of MMC, Primary Closure $(n=40)$ & $6(15 \%)$ & 0 \\
C: Conjunctival Autograft $(n=40)$ & $2(5 \%)$ & 0 \\
\hline
\end{tabular}

mitomycin $\mathrm{C}$ injections were first noted at 2 months' followup $(2$ cases $)$ while others were observed on the $3^{\text {rd }}$ month (4 cases). Similarly, in the group where mitomycin $\mathrm{C}$ was used intraoperatively, three cases of recurrence were first noted on the $2^{\text {nd }}$ month, while the other three cases were reported on the $6^{\text {th }}$ month of follow-up. Recurrences in the conjunctival autograft group were observed on the $2^{\text {nd }}$ month and the $6^{\text {th }}$ month of follow-up.

At the end of the study period, one complication of scleral thinning was reported in the group who underwent preoperative injection of mitomycin $\mathrm{C}$, while there were no other complications noted in the other groups (Table 2). Complication rates among groups have no statistically significant difference $(\mathrm{P}=1.00)$.

\section{DISCUSSION}

This study showed that there were no statistically significant differences for recurrence and complication rates among the three techniques: preoperative subpterygeal injection of mitomycin $\mathrm{C}$, intraoperative use of mitomycin $\mathrm{C}$, and conjunctival autograft. Nevertheless, conjunctival autograft offers the theoretical advantages of reconstructing the architecture of the corneo-scleral limbus. By acting as a barrier for pterygium growth and transplanting limbal cell stems, it may facilitate corneal epithelial healing. ${ }^{6}$ Conjunctival autograft is generally considered as the procedure of choice in the treatment of primary and recurrent pterygium due to its low recurrence rates and safety. ${ }^{8,15}$ However, compared to other treatment options, conjunctival autograft requires greater surgical skills and is more time- consuming.

Mitomycin $\mathrm{C}$ has been utilized in the management of pterygium since 1988 due to its ability to reduce pterygium recurrence. Despite the reported decrease in recurrence rates, complications have also been reported with the use of intraoperative mitomycin $\mathrm{C}$, such as punctate keratitis, chemosis, delayed conjunctival healing, conjunctival granuloma, scleral melting and corneal melting. Long-term effects may include scleral thinning, melting and possible damage to the ocular surface epithelium. ${ }^{9}$ To reduce the risk of complications of intraoperative application of mitomycin $\mathrm{C}$, several studies reported success in using pre-operative subpterygeal/subconjunctival injection of mitomycin $\mathrm{C}$ 1 month prior to pterygium excision, noting low rates of recurrence and complications. Donnenfeld et. al. reported $6 \%$ recurrence rate with no complications noted after 2 years of follow up, ${ }^{1}$ while Chang et. al. had no recurrence or adverse effects in their patients after 2 years of follow-up. ${ }^{9}$ Similarly, Khakshoor et. al. noted no recurrence in patients who underwent preoperative injection of mitomycin $\mathrm{C}$ after at least 12 months of follow-up. ${ }^{13}$ In this study, recurrence rates of preoperative injection and intraoperative application of mitomycin-C are the same (6 patients, 15\%) after 24 months of follow up. The higher recurrence rate in the study could be related to the concentration of mitomycin $\mathrm{C}$ injected and applied and the duration of exposure to mitomycin $\mathrm{C}$ in the intraoperative mitomycin $\mathrm{C}$ group.

Previous studies on preoperative subconjunctival injection of mitomycin $\mathrm{C}$ has reported minimal complications, such as cases of hypovascularity and whitening of the sclera at the site of pterygium excision. ${ }^{13}$ In our study, there was 1 reported case of scleral thinning in those given preoperative subconjunctival injection of mitomycin $\mathrm{C}$, although there was no significant difference among the groups for complication rates $(\mathrm{P}=1.00)$. Scleral hypovascularity and delayed epithelial healing was noted on the $2^{\text {nd }}$ month of follow up. Although revision of the medications, specifically 
the corticosteroid and lubricants, was done, on subsequent follow-up, there was little improvement despite various combinations of topical eyedrops. Scleral melting associated with the use of adjunct mitomycin $\mathrm{C}$ in pterygium excision has been attributed to leaving a large area of bare sclera. This results in failure of the wound to epithelialize, which may lead to vascular compromise and permanent inhibition of fibroblast proliferation, exposed sclera, and eventually, avascular necrosis. Mitomycin C-related complications may be attributed to poor patient selection (i.e., patients having prior ocular surface disease or immune disorders), poor follow up and post-operative management. ${ }^{9}$ The case of scleral thinning in our series was reported in an elderly female patient who may have been at high risk for developing dry eye disease; thus susceptible to delayed healing of the epithelium. This patient developed thinning but the uvea was not exposed. She was just maintained on topical ointment and preservative-free tear substitutes as well as frequent monitoring of the degree of thinning. In case of progressive weakening, different surgical procedures may be done - lamellar scleral patch graft from a donor sclera or multilayered amniotic membrane grafts for the thinned-out area.

To the best of our knowledge, this is the only study comparing these three surgical procedures. The 24-month follow-up period is acceptable to detect short- and mediumterm potential complications of the surgery. However, long-term complications could not be ruled out based on our study.

\section{CONCLUSION}

There are no significant differences in the recurrence and complication rates among the three pterygium excision techniques. Preoperative subconjunctival or subpterygeal injection and intraoperative application of mitomycin $\mathrm{C}$ with pterygium excision are both equally effective in reducing recurrence of pterygium, but more careful patient selection and follow-up must be done to prevent complications such as scleral thinning.

\section{Statement of Authorship}

ALDA - Conceptualization of the research, data analysis, and approval of final version, TGBM - Data collection, analysis and discussion, MAP - Data collection and initial paper writing, and JVT - Data analysis, statistics, and final paper writing.

\section{Author Disclosure}

All authors declared no conflicts of interest.

\section{Funding Source}

None.

\section{REFERENCES}

1. Donnenfeld ED, Perry HD, Fromer S, Doshi S, Solomon R, Biser S. Subconjunctival mitomycin $\mathrm{C}$ as adjunctive therapy before pterygium excision. Ophthalmology. 2003 May; 110(5):1012-6.

2. Threlfall TJ, English DR. Sun exposure and pterygium of the eye: A dose-response curve. Am J Ophthalmol. 1999 Sep; 128(3):280-7.

3. Nemesure B, Wu SY, Hennis A, Leske MC, Barbados Eye Studies Group. Nine-year incidence and risk factors for pterygium in the Barbados eye studies. Ophthalmology. 2008 Dec; 115(12):2153-8.

4. Saw SM, Tan D. Pterygium: prevalence, demography and risk factors. Ophthalmic Epidemiol. 1999 Sep; 6(3):219-28.

5. Wong TY, Foster PJ, Johnson GJ, Seah SK, Tan DT. The prevalence and risk factors for pterygium in an adult Chinese population in Singapore: the Tanjong Pagar survey. Am J Ophthalmol. 2001 Feb; 131(2):176-83.

6. Sanchez-Thorin JC, Rocha G, Yelin JB. Meta-analysis on the recurrence rates after bare sclera resection with and without mitomycin- $\mathrm{C}$ use and conjunctival autograft placement in surgery for primary pterygium. Br J Ophthal. 1998 Jun; 82(6):661-5.

7. Hirst LW. The treatment of pterygium. Surv Ophthalmol. 2003 Mar-Apr; 48(2):145-80.

8. Ang LPK, Chua JLL, Tan DTH. Current concepts and techniques in pterygium treatment. Curr Opin Ophthalmol. 2007 Jul; 18(4):308-13.

9. Chang YS, Chen WC, Tseng SH, Sze CI, Wu CL. Subconjunctival mitomycin C before pterygium excision. Cornea. 2008 May; 27(4): 471-5.

10. Young AL, Leung GYS, Wong AKK, Cheng LL, Lam DSC. A randomized trial comparing $0.02 \%$ mitomycin $\mathrm{C}$ and limbal conjunctival autograft after excision of primary pterygium. $\mathrm{Br} \mathrm{J}$ Ophthalmol. 2004 Aug; 88(8):995-7.

11. Solomon A, Kaiserman I, Raiskup FD, Landau D, Frucht-Pery J. Long-term effects of mitomycin $\mathrm{C}$ in pterygium surgery on scleral thickness and the conjunctival epithelium. Ophthalmology. 2004 Aug;111(8):1522-7.

12. Seong GJ, Park C, Kim CY, Hong YJ, So HS, Kim SD, et al. Mitomycin $\mathrm{C}$ induces the apoptosis of human Tenon's capsule fibroblast by activation of c-Jun N-terminal kinase 1 and caspase-3 protease. Invest Ophthalmol Vis Sci. 2005 Oct; 46(10):3545-52.

13. Khakshoor H, Razavi ME, Daneshvar R, Shakeri MT, Ghate MF, Ghooshkhanehi H. Preoperative subpterygial injection versus intraoperative mitomycin $\mathrm{C}$ for pterygium removal: comparison of results and complications. Am J Ophthalmol. 2010 Aug;150(2):193-8.

14. dela Hoz F, Montero JA, Alió JL, Javaloy J, Ruiz-Moreno JM, Sala E. Efficacy of mitomycin $\mathrm{C}$ associated with direct conjunctival closure and sliding conjunctival graft for pterygium surgery. $\mathrm{Br} \mathrm{J}$ Ophthalmol. $2008 \mathrm{Feb}$; 92(2):175-8.

15. Agahan ALD, Astudillo PP, dela Cruz RC. Comparative study on the use of conjunctival autograft with or without mitomycin-C in pterygium surgery. Philipp J Ophthalmol. 2014 Jul-Dec; 39(2):73-7. 